\title{
BRCAI expression regulation and its role as a biomarker of cancer
}

\section{Editorial}

Tumor suppressor $B R C A 1$ prevents the development of several cancers, mainly breast and ovarian cancer. The main function of $B R C A 1$ is the repair of DNA damage through homology recombination. ${ }^{1,2}$ The disruption of this $B R C A 1$ function leads to the development of several oncological diseases, in particular, breast cancer, ovarian cancer and also non-small cell lung cancer. Recently, it became clear that $B R C A 1$ can serve as a prognostic marker of the course of several oncological diseases and as a predictive marker of platinum-based therapy. Since the discovery of BRCA1 in early 1990 extensive studies of its biological function and mechanisms of its expression were carried out. Together with its associated proteins $B R C A 1$ is involved in the repair of DNA double strand breaks through homologous recombination mechanism. ${ }^{2}$ Fine tuning of $B R C A 1$ protein level is important for its balanced function in homologous recombination and therefore in the maintenance of genomic stability. Several molecular mechanisms of $B R C A 1$ gene alterations and $B R C A 1$ gene expression regulation were revealed. These mechanisms include germinal and sporadic mutations in $B R C A 1$ gene, ${ }^{3}$ epigenetic mechanisms of the disruption of $B R C A 1$ gene expression including methylation of $\mathrm{CpG}$ islands $\mathrm{s}^{4,5}$ and covalent histone modifications in the promoter and coding region of $B R C A 1$ gene, regulation with transcription factors ${ }^{6}$ loss of one allele of $B R C A 1$ gene (so called loss of heterozigosity, $\mathrm{LOH})^{7}$ and possibly amplification of $B R C A 1$ gene. ${ }^{8}$ It has been demonstrated that these mechanisms could be the cause of $B R C A 1$ function disruption and further could lead to the development of cancer.

In addition to well studied biological function of $B R C A 1$ in homologous recombination and mechanisms of regulation of its expression, recently the role of $B R C A 1$ as a biomarker of several oncological diseases emerged. It was shown that decreased levels of $B R C A 1$ protein and mRNA often correlated with the development of breast and ovarian cancer and that the level of $B R C A 1$ protein and mRNA could predict favorable/unfavorable course of the disease. ${ }^{9}$ Therefore, BRCAl could function as a prognostic marker of the disease course. Moreover, it was demonstrated that decreased levels of BRCA1 protein and mRNA correlated with decreased resistance to platinum-based chemotherapy. ${ }^{10-12}$ Therefore, BRCA1 could be a predictive marker of platinum chemotherapy efficiency. Taken together, BRCA1 perfectly corresponds to the definition of the biomarker. The biomarker has three main characteristics that include, first of all, a defined biological function, second, quantitative methods of its detection and third, the availability of patient cohorts of reasonable size to be studied. Firstly, it has defined biological function participating in the repair of DNA double strand breaks via homologous recombination. Secondly, there are several very precise methods allowing to measure quantities of BRCA1 protein and mRNA. Thirdly, patient cohorts of reasonable size are available for analysis. Altogether, BRCA1 protein emerges in recent years as the prognostic marker of the course of oncological diseases and as the predictive marker of the efficiency of platinum-based chemotherapy that is extensively used in the treatment of $B R C A 1$-dependent cancers.
Volume 2 Issue 5 - 2015

\section{Elena A Shestakova}

N.N. Blokhin Russian Cancer Research Center, Russian Federation

Correspondence: Elena A. Shestakova, Federal State Budgetary Scientific Institution "N.N.Blokhin Russian Cancer Research Center" of the Ministry of Health of the Russian Federation, Kashirskoe shosse 24, I I5478, Moscow, Russian Federation, Tel +7499612 8072, Email labmedchem@mail.ru

Received: October 21, 2015 | Published: November 4, 2015

\section{Acknowledgements}

Dr. Elena A. Shestakova holds a position of Senior Research Scientist, PhD at N.N. Blokhin Russian Cancer Research Center, Moscow, Russian Federation.

\section{Conflict of interests}

Author declares that there is no conflict of interest.

\section{References}

1. Moynahan ME, Chiu JW, Koller BH, et al. Brcal controls homologydirected DNA repair. Mol Cell. 1999;4(4):511-518.

2. Jiang Q, Greenberg RA. Deciphering the BRCA1 tumor suppressor network. J Biol Chem. 2015;290(29):17724-17732.

3. Wong-Brown MW, Meldrum CJ, Carpenter JE, et al. Prevalence of BRCA1 and BRCA2 germline mutations in patients with triple-negative breast cancer. Breast Cancer Res Treat. 2015;150(1):71-80.

4. Esteller M, Silva JM, Dominguez G, et al. Promoter hypermethylation and BRCA1 inactivation in sporadic breast and ovarian tumors. J Natl Cancer Inst. 2000;92(7):564-569.

5. Wong EM, Southey MC, Fox SB, et al. Constitutional methylation of the BRCA1 promoter is specifically associated with BRCA1 mutationassociated pathology in early-onset breast cancer. Cancer Prev Res. 2011;4(1):23-33.

6. McCoy ML, Mueller CR, Roskelley CD. The role of the breast cancer susceptibility gene 1 (BRCA1) in sporadic epithelial ovarian cancer. Reproductive Biol Endocrinol. 2003;1:1-5.

7. Russel PA, Pharoah PD, De Foy K, et al. Frequent loss of BRCA1 mRNA and protein expression in sporadic ovarian cancers. Int $J$ Cancer. 2000;87(3):317-321.

8. Ribeiro IP, Marques F, Caramelo F, et al. Genetic gains and losses in oral squamous cell carcinoma: impact on clinical management. Cell Oncol. 2014;37(1):29-39.

9. Thrall M, Gallion HH, Kryscio R, et al. BRCA1 expression in a large series of sporadic ovarian carcinomas: a Gynecologic Oncology Group study. Int J Gynecol Cancer. 2006;16(Suppl 1):166-171. 
10. Carser JE, Quinn JE, Michie CO, et al. BRCA1 is both a prognostic and predictive biomarker of response to chemotherapy in sporadic epithelial ovarian cancer. Gynecol Oncol. 2011;123(3):492-498.

11. Weberpals JI, Tu D, Squire JA, et al. Breast cancer 1 (BRCA1) protein expression as a prognostic marker in sporadic epithelial ovarian carcinoma: an NCIC CTG OV.16 correlative study. Ann Oncol. 2011;22(11):2403-2410.
12. Byrski T, Huzarski T, Dent R, et al. Pathologic complete response to neoadjuvant cisplatin in BRCA1-positive breast cancer patients. Breast Cancer Res Treat. 2014;147(2):401-405. 